(3) Occasionally there are striking similarities in the elements of two planets, e.g.

$\begin{array}{lcccccccccccc} & a & e & & i & & 8 & & \omega \\ \text { (251) Sophie } & \ldots & 3^{\circ} 10 & \ldots & 0^{\circ} 09 & \ldots & 10^{\circ} & 29^{\prime} & \ldots & 157^{\circ} & \ldots & 80^{\circ} & 16^{\prime} \\ \text { (318) Magdalena.. } & 3.19 & \ldots & 0.07 & \ldots & 10^{\circ} & 33^{\prime} & \ldots & 163^{\circ} & \ldots & 80^{\circ} & 5^{\prime}\end{array}$ The resemblance of the elements in the case quoted is far closer than is reasonably probable, even for a selected pair out of several hundred planets. We, however, are much inclined to doubt whether it is more than an accident. A famous case of coincidence is that between the periods of rotation and revolulution of the moon. Here there is a controlling cause tending to produce equality, and the equality is exact. Now in the case of the elements of Sophie and Magdalena, we suppose that there are only three possible hypotheses:--.(i.) accidental resemblance; (ii.) a cause tending to produce similarity; (iii.) a common origin with no subsequent connection. We may take as analogies:-(i) two watches that have run down, but happen by accident to show nearly the same time; (ii.) two clocks synchronised with each other; (iii.) two clocks, each constructed with the same sbject of exhibiting mean time, but entirely independent of each other subsequently. Now, as regards (ii.), we may remark that in the present instance the supposed controlling force has done its work very imperfectly. The objection to (iii.) is that a common origin hypothesis can only be applied in a few isolated cases, of which the above is one, and therefore we ourselves feel inclined to fall back upon (i.), the hypothesis of accidental resemblance, although we fully admit its antecedent improbability.

In the early part of the book an estimate is given of the total mass of the asteroids. It would appear that the entire mass is very far short of a quarter of the mass of the earth, very far short indeed of the mass that would have been expected if a single planet had filled the gap in Bode's law between Mars and Jupiter.

In a few cases approximate linear dimensions are given, founded on measures by Barnard in 1894 .

We must congratulate M. Mascart on a very interesting and exhaustive work. We regret, however, the absence of a complete list of all known asteroids with their elements. We should have been glad to have seen such a list in several different forms, with the small planets arranged in order of mean motion, eccentricity, longitude of perihelion, and in the various other ways mentioned in the book. It would have enabled us to follow the arguments from statistics with greater appreciation, and the value of the book as a work of reference twould have been much increased. The work admirably fulfits the design of the author.

\section{SIR BENJAMIN BAKER, K.C.B., F.R.S.}

SIR BENJAMIN BAKER, whose sudden death in his sixty-seventh year we recorded last week, had a distinguished career as an engineer, and was concerned more or less directly with most of the great engingering schemes of recent years. By his death the profession of civil engineering is deprived of one of its leading members, and the scientific world of a man who combined scientific knowledge with practical training and experience. He was a constant contributor to early volumes of NATURE, and his writings and addresses cover a wide field of applied science.

Sir Benjamin Baker was born in 1840 , and for the last thirty years or so was engaged in the design and construction of important engineering works at home and abroad. He carried out numerous investigations relating to the strength of materials and of engineering structures generally, and contributed papers thereon to various scientific societies. He was the author of "A Theoretical Investigation into the Most Advantageous System of Constructing Bridges of Great Span," upon which plan the Forth Bridge and six of the largest bridges in the world have been built.

His name will be remembered chiefly in connection with the Forth Bridge and the great dam across the Nile at Assouan. On the completion, in 1890, of the former engineering feat Sir Benjamin Baker was made K.C.M.G., and when the dam at Assouan was finished in 1902 he was made K.C.B., and received at the same time the first-class of the Order of the Medjidieh from the Khedive. Two years ago plans were submitted to him for the raising of the Assouan dam, and since then he had worked more or less continuously at the subject of stresses on dams. A note by him upon the project appeared in the Earl of Cromer's recent despatch respecting the water supply of Egypt; and in it he stated that a design had been evolved which satisfied all the theoretical and practical conditions, and rendered the storage of nearly two and a half times the present quantity of water in the reservoir a simple problem.

Though his name will always be associated first with the famous works mentioned, Sir Benjamin Baker took a very active part in other great engineering enterprises in many parts of the world. He had ing enterprise with making the Metropolitan Railway, and was associated more recently with the construction of the various tubes for electric traffic under London.

Sir Benjamin Baker was elected a Fellow of the Royal Society in 1890 , and in 1895 he became president of the Institution of Civil Engineers. Honorary degrees were conferred upon him by the Universities of Cambridge and Edinburgh, by the Irish Academy, and other learned bodies. He was closely associated with the various engineering societies, and was actively interested in the work of the British Association and the Royal Institution. He was a member of the council of the Institution of Mechanical Engineers and an honorary member of the American and Canadian Societies of Civil Engineers, and the American Society of Mechanical Engineers. His unexpected death will be deplored wherever pure and applied science are studied, and his personal friends have suffered a loss that cannot easily be realised by those who did not know his broad interests and sympathetic nature.

\section{NOTES.}

The Serte of the State of Pennsylvania has voted 7o,oool the American Philosophical Society to provide a. fitting memorial to Beniamin Franklin.

Sir Willam Ramsay, K.C.B., has received through the Foreign fifice the Order of Commendatore della Corona d'Italia fom the King of Italy, together with King Edward's permission to wear it.

AT the anniversary meeting of the Linnean Society on May 24, ting Linnean medal, awarded by the council to Dr. Melcb or Treub, director of the State Botanic Garden at Buiroyrg, Java, was formally handed to Mr. Van Royen, conncillor of the Netherlands Legation, who undertook to transmit the medal to Dr. Treub.

Mr. ANDREW WATT has been elected meteorological secretary of the Scottish Meteorological Society in sucession to the late Dr. Buchan, F.R.S. Mr. Watt has since 1900 been closely associated with Dr. Buchan in the discussion of rainfall and other important meteorological problems.

No. I96I, VOL. 76] 